\title{
Escola Popular de Comunicação Crítica: uma experiência contra-hegemônica na periferia do Rio de Janeiro ${ }^{1}$
}

\author{
Eduardo Granja Coutinho \\ UFRJ \\ Raquel Paiva3 \\ UFRJ
}

\begin{abstract}
Resumo: $O$ presente trabalho tem como objetivo refletir sobre a experiência da Escola Popular de Comunicação Crítica (ESPOCC), uma escola pioneira voltada para a formação de repórteres populares, capazes de afirmar a identidade de um grupo social historicamente marginalizado e expressar uma visão das comunidades populares diferente daquela veiculada pela grande mídia. Entendida aqui como um instrumento de contra-hegemonia, a ESPOCC tem como objetivo estimular a formação de núcleos de comunicação comunitária na periferia da cidade do Rio de Janeiro.
\end{abstract}

Palavras-Chave: comunicação comunitária, contra-hegemonia, monopólio da mídia, mídia alternativa.

\begin{abstract}
The purpose of this text is to impart in outline form the experience of the Popular School of Critical Communication (ESPOCC), which pioneers the training of youth from the outskirts of Rio de Janeiro, in order to qualify them as civic reporters. They are expected to assert the social identity of neighborhoods set apart from the global society and to provide images of popular communities indeed different from those spread abroad by the regular mass media. ESPOCC is supposed to be a counter-hegemonic device, the main purpose of which is to foster the scattering of civic communication in Rio.
\end{abstract}

Keywords: communitarian communication, counter-hegemony, media monopoly, alternative media.

\footnotetext{
${ }^{1}$ Comunicação apresentada no Coloquio internacional sobre educación radiofónica y medios comunitarios: participación, sostenibilidad e identidad, por ocasião do aniversário de 50 anos da Rádio Santa Maria, celebrado na Pontifícia Universidad Católica "Madre y Maestra", Santiago de los Caballeros, República Dominicana, de 27 a 29 de novembro de 2006. 2 Eduardo Granja Coutinho é professor adjunto da Escola de Comunicação da UFRJ e autor dos livros Velhas histórias, memórias futuras: o sentido da tradição na obra de Paulinho da Viola (EdUERJ, 2002) e Os cronistas de Momo: imprensa e carnaval na Primeira República (Editora UFRJ, 2006).

3 Raquel Paiva é professora associado da Escola de Comunicação da UFRJ, pesquisadora 1B do CNPQ, autora de inúmeros artigos em periódicos especializados, possui 8 livros publicados, dentre eles O Espírito Comum - mídia, globalismo e comunidade, (1997), pela Editora Mauad. Realizou especialização no Ciespal, no Equador em 1985. Mestrado e Doutorado pela ECO/UFRJ, com co-orientação pelo filosofo italiano Gianni Vattimo, na Universitá degli Studi de Torino, de quem traduziu para o português algumas das suas obras. Diretora cultural da Intercom e coordenadora do Laboratório de Estudos em Comunicação Comunitária (LECC), exerceu a secretaria-geral da Compós de 2001-2003 e a coordenação do Programa de Pós Graduação em Comunicação da ECO/UFRJ no período 2003-2005. Prêmio Liderança Emergente da Intercom, em 2005.
} 


\section{Aprende - lê nos livros \\ Lê nos olhos - aprende \\ A ler nos jornais: \\ A verdade pensa com a tua cabeça. \\ Faça perguntas sem medo \\ Não te convenças sozinho \\ Se não descobriu por si \\ Na verdade não descobriu.}

(Bertolt Brecht)

Antes de mais nada, gostaríamos de agradecer o convite da RNW e reafirmar a importância de se homenagear uma rádio como a Santa Maria, há 50 anos ao lado do povo na luta pela democracia e afirmação de sua identidade cultural. Sabemos das dificuldades vividas por esta emissora ao longo desse período e, solidarizando-nos, viemos lhes falar das dificuldades de quem trabalha com comunicação comunitária no Brasil - do absurdo monopólio da imprensa, da repressão policial às rádios livres e comunitárias, do crescimento espantoso das rádios evangélicas comerciais, da representação preconceituosa e distorcida dos espaços populares difundida pela grande mídia, etc. Mas não falaremos apenas das dificuldades. Gostaríamos de lhes trazer também uma boa notícia: neste mês de outubro passado, formou-se a primeira turma de alunos da Escola Popular de Comunicação Crítica (ESPOCC), na periferia da cidade do Rio de Janeiro.

A ESPOCC é uma experiência pioneira no campo do ensino de comunicação no Brasil. É a primeira escola voltada para a formação de repórteres populares, capazes de pensar e expressar uma visão de mundo diferente daquela veiculada pela grande mídia, no sentido de afirmar a identidade de um grupo social historicamente marginalizado. Esta é a boa nova: há, numa favela carioca, uma instituição de ensino organizada por diversas entidades da sociedade civil, que tem como objetivo estimular a formação de núcleos de comunicação comunitária nos espaços populares da cidade. 
Esta escola - uma esperança para nós que lutamos contra o oligopólio dos meios de comunicação - nasce da clara convicção de que, para os que se encontram sob a dominação dos grandes meios, não há outro caminho senão a articulação de uma rede popular e alternativa de comunicação crítica.

\section{Meios comunitários no contexto de oligopólio e repressão}

O significado da experiência da Escola Popular de Comunicação Crítica (ESPOCC) na cultura da cidade será melhor avaliado se a situarmos no contexto da comunicação no país.

No Brasil, como na maioria dos países da América Latina, o cenário da comunicação é marcado por uma mídia extremamente concentrada nas mãos de poucos e intimamente associada aos interesses de elites nacionais e estrangeiras.

Hoje, sete grupos controlam 80\% de tudo o que é visto, ouvido e lido no país. Neste oligopólio, a Rede Globo, da família Marinho, sobressai-se com grande destaque. Com mais da metade da audiência da TV aberta e $74 \%$ das verbas publicitárias, a Globo é, há quatro décadas, a grande formadora de consciências no Brasil.

Vale lembrar que o poderoso império de Roberto Marinho nasceu, cresceu e se tornou o que é durante os anos de ditadura militar, constituindo-se como uma espécie de porta-voz do regime. Sua implementação e rápida expansão foram viabilizadas pela transferência de capital e know-how do grupo norte-americano Time-Life para aquela empresa. Nos anos 6o, foram assinados dois contratos entre a Time-Life e a Globo, violando a legislação brasileira que impedia a participação estrangeira no setor de comunicações. Este acordo foi fundamental para a empresa brasileira, porque lhe garantiu "financiamento e acesso a informação privilegiada sobre métodos de gestão no setor televisivo. Em apenas cinco anos, entre 1962 e 1967, a Globo passou a dominar o mercado audiovisual brasileiro".

Pode-se perguntar qual o interesse de um grupo de comunicações norteamericano em criar uma televisão forte como a Rede Globo - a quarta maior emissora de TV do mundo - num país como o Brasil. É preciso notar que a Globo fechou esse acordo com a revista Time-Life na mesma época em que os Estados Unidos 
articulavam o golpe militar no país, o que demonstra que essa transferência de capital visava, antes de mais nada, dar sustentação ideológica à ditadura militar, apoiada e supervisionada pela CIA. Como observou um importante historiador brasileiro, “O imperialismo controla a informação na área onde exerce seu domínio".

Esse é o tema do documentário realizado pela BBC de Londres, "Brasil: muito além do Cidadão Kane". O título do filme sugere uma comparação entre o dono das Organizações Globo, Roberto Marinho, e o magnata da imprensa norteamericana William Randolph Hearst, em quem Orson Welles se inspirou para criar o clássico Cidadão Kane. A idéia do filme é a de que o monopólio da Globo está muito além do de Hearst nos EUA. A concentração da mídia no Brasil é incomparavelmente maior do que a pemitida pela legislação estadunidense. Isso fez de Roberto Marinho, falecido em 2003, o homem mais poderoso do Brasil.

Ainda hoje - mesmo após a morte do patriarca - a Globo dá as cartas na política brasileira, sendo capaz de fazer e desfazer chefes de Estado. Sempre em sintonia com interesses dominantes, ela é, atualmente, a principal responsável pela criação das condições ideológicas necessárias para a implementação de medidas neoliberais no país (privatização de empresas públicas, flexiblização das leis trabalhistas, reforma da Previdência, etc.).

O poder dos grandes meios de comunicação, particularmente da Globo, muitas vezes se confunde com o do próprio Estado; outras, coloca-se acima dos governos que, em troca de indispensável apoio da mídia, se submetem aos seus desígnios. Basta pensar que os rumos da política de comunicação no país são praticamente definidos por essas grandes empresas, de acordo com seus interesses e expectativas. Veja-se, por exemplo, a atuação do atual ministro das comunicações ex-funcionário da emissora dos Marinho - em defesa do modelo de TV digital reivindicado tacitamente pelos donos do poder, em detrimento de um outro modelo o brasileiro -, mais democrático, aberto e barato.

A relação de promiscuidade do poder público com a grande mídia tem como contrapartida a coerção policial, jurídica e burocrática aos meios de comunicação comunitária. 
No Congresso, o poderoso lobby dos radiodifusores comerciais trata de barrar qualquer projeto que represente uma ameaça de democratização da comunicação. Tais lobistas contam com a conivência do poder executivo. A inexistência de uma política ativa do governo para as rádios livres e comunitárias e a sua morosidade em analisar pedidos de novas concessões acabam por transformar "o dial num terreno reservado quase que exclusivamente para as rádios comerciais”.

A má vontade dos sucessivos governos para com as rádios comunitárias contrasta com a agilidade da Agência Nacional de Telecomunicações (Anatel) em reprimir as emissoras populares. Entre 1998 e 2002, mais de 10 mil pessoas foram indiciadas, e 3.623 foram condenadas por radiodifusão clandestina no Brasil.

No mesmo período havia mais de 8 mil pedidos de concessão de rádios comunitárias ainda sem definição. $80 \%$ desses pedidos são arquivados por não cumprimento de quesitos burocráticos. "O processo completo para a liberação de uma rádio comunitária tem levado até oito anos. Como se pode prever, elas não esperam tanto tempo e começam a funcionar, clandestinamente. À Anatel cabe fechar e lacrar, indiscriminadamente, qualquer emissora sem outorga, como a Rádio Heliópolis, ou como uma rádio que funcionava dentro da Universidade de São Paulo, e também milhares de outras Brasil afora. Este ano [2006], a Anatel fechou cerca de 800 emissoras".

Há diversas denúncias de abusos nas ações da Polícia Federal em conjunto com a Anatel para fechar emissoras populares. Rádios comunitárias são interditadas e o seu material apreendido - muitas vezes sem nenhum mandado judicial -, seus representantes presos e processados. Como foi o caso da Rádio Bicuda (Vila da Penha, RJ), que tem um trabalho importante de preservação do meio ambiente e organização dos diversos movimentos sociais da Leopoldina. A entidade foi fechada com violência por agentes da Polícia Federal em 2002. Foram levados todos os equipamentos e seus representantes presos. A comunidade se sentiu acuada. A força da ação foi tema de debates em vários outros meios de comunicação. Os equipamentos foram recuperados, mas a entidade não pôde recolocar a sua radio no ar. O seu pedido de concessão, feito em 1999, foi arquivado e a outorga foi dada a uma rádio comercial. 


\section{Comunicação popular e contra-hegemonia}

Pelo modo como se dá a repressão às rádios comunitárias, não é difícil compreender a ameaça que elas representam ao projeto de hegemonia das elites. $\mathrm{O}$ pânico mal dissimulado que a utilização popular desses meios de comunicação provoca nas classes dirigentes fortalece a nossa convicção de que o desenvolvimento de jornais, rádios e TVs comunitários é uma estratégia vital na luta por uma nova cultura.

Como observou Antonio Gramsci, a luta por uma nova cultura, capaz de se contrapor à visão de mundo dominante se dá no âmbito da sociedade civil, entendida como o conjunto das organizações responsáveis pela elaboração e difusão das ideologias: escolas, igrejas, partidos, sindicatos, ONGs, meios de comunicação, etc.

É na sociedade civil que os diferentes grupos sociais lutam para construir e impor a sua visão de mundo, sua liderança intelectual e moral. E é lá que atuam os chamados "intelectuais orgânicos", aqueles que estão organicamente ligados a uma determinada classe social, tendo como função organizar a visão de mundo deste grupo.

Gramsci fala em intelectuais orgânicos das classes dominantes e intelectuais orgânicos das classes subalternas. Os primeiros são responsáveis pela construção da hegemonia da burguesia e atuam em seus aparelhos, partidos, associações e entidade de classe. (A televisão é hoje, sem dúvida, o principal e mais eficiente instrumento de hegemonia dos grupos dominantes. Há quem a veja como uma espécie de "príncipe eletrônico", um intelectual orgânico, criador difusor da consciência política das elites.)

Por sua vez, os intelectuais que trabalham nas organizações dos trabalhadores (partidos, sindicatos, movimentos) e na imprensa comunitária, contribuem para tornar orgânica a visão de mundo das camadas subalternas, criando e difundindo uma consciência crítica capaz de exprimir os anseios das massas.

Daí a importância, nota Gramsci, de se formarem intelectuais portadores de uma vontade coletiva popular; intelectuais, poderíamos acrescentar, que dominem linguagens, tecnologias e procedimentos por meio dos quais possam comunicar ao maior número de pessoas, conhecimentos, valores e idéias não hegemônicos. 
"Pensar hoje projetos de ação político-social na cidade do Rio de Janeiro e em cenários geopolíticos mais amplos exige a valorização da intervenção no campo da comunicação. Principalmente ao se ter em mente que os dispositivos tecnológicos de mídia são hoje o alicerce sob a qual se escoram as dinâmicas culturais do mundo globalizado".

Foi precisamente o imperativo da luta por uma nova comunicação e o reconhecimento da importância dos meios comunitários como "instrumentos de hegemonia" que orientou a criação da Escola Popular de Comunicação Crítica, um curso destinado a formar jovens aptos a produzir novos discursos, novas narrativas e novos olhares sobre os espaços populares.

\section{A Escola Popular de Comunicação Crítica}

A Escola Popular de Comunicação Crítica (ESPOCC) foi idealizada por uma organização não-governamental, o Observatório de Favelas do Rio de Janeiro, coordenado pelo professor Jailson de Souza, e tem como parceiros a Universidade Federal do Rio de Janeiro (na figura do Laboratório de Comunicação Comuniária, o LECC), a Universidade Federal Fluminense, o Canal de Televisão Futura, o Sindicato de Jornalistas do Rio de Janeiro, a Associação Brasileira de Jornalismo Investigativo, a associação cultural Afro-reggae e a Associação Brasileira de Produtores de Vídeo que, juntos, formam o conselho responsável pelo gerenciamento da escola.

As atividades da ESPOCC foram iniciadas em 2005 nas instalações do Observatório de Favelas, localizado no complexo de favelas da Maré, Zona Norte do Rio de Janeiro. Sua primeira turma, recém-formada, reuniu 42 alunos, moradores de diversos espaços populares: as favelas da Maré, do Caju, de Manguinhos, do Alemão, do Jacarezinho, de Vigário Geral e de Parada de Lucas. A maioria desses alunos jovens com o ensino médio completo - já tinham algum tipo de inserção nos movimentos sociais de suas comunidades: uns militavam em associações de moradores, outros já trabalhavam com comunicação comunitária, quase todos revelaram uma consciência crítica bastante aguçada. É de se notar o esforço que estes alunos - negros, mulatos e brancos pobres - fizeram para estudar. Muitos deles iam para a Escola depois de um dia inteiro de trabalho (a Escola lhes paga a passagem de ônibus) e ainda assim chegavam com energia para discutr, questonar, aprender. 
A ESPOCC conta com três professores contratados e a participação voluntária de professores universitários, alunos de pós-graduação e profissionais da área de comunicação. É de se notar que o surgimento da ESPOCC gerou grande expectativa e entusiasmo junto aos professores que, de alguma forma, lutam pela democratização da mídia no Brasil. Nós do Laboratório de Estudos de Comunicação Comunitária da UFRJ, por exemplo, vimos na ESPOCC a possibilidade de estabelecer um vínculo entre a academia e as comunidades populares; entre a teoria crítica da comunicação e um projeto ético-político voltado para a construção de cidadania nas zonas periféricas da cidade.

Visando a formação intelectual e profissonal dos adolescentes e jovens moradores de favelas, a ESPOCC pretende estimular a criação de núcleos locais de comunicação e cultura nas comunidades, assim como encaminhar estes jovens ao mercado de trabalho, a partir de parcerias com empresas públicas e privadas, cooperativas populares e outras entidades.

Sendo caracterizado, formalmente, como curso de extensão, de caráter profissionalizante, a ESPOCC concede ao aluno o título de tecnólogo de comunicação. Ao final do curso, os alunos recebem um certificado fornecido de forma conjunta pela Universidade Federal do Rio de Janeiro (UFRJ) e pela Universidade Federal Fluminense (UFF).

Quanto ao currículo, a ESPOCC oferece disciplinas no campo da mídia impressa, da produção em vídeo, da fotografia, da rádio comunitária, da comunicação via internet, além de uma formação básica em informática e inglês. Eis, em linhas gerais, as ementas dessas disciplinas:

- Vídeo - Apresentação, discussão e prática das principais linguagens e formatos audiovisuais. Roteiro, direção e produção em vídeo. História e reflexão do impacto das tecnologias audiovisuais na cultura moderna. Produção do áudio-visual e o universo popular: tvs de rua, comunitária, vídeo popular.

- Fotografia - Conceituação e manuseio de equipamentos fotográficos. História da fografia. Noções de fotojornalismo. Fotografia documental.

- Mídia Impressa - Introdução à comunicação escrita. Oficina de textos. Elaboração de projeto gráfico (jornal, cartilha, folder, zine, quadrinhos). 
- Rádio Comunitária - Do roteiro à direção na produção em rádio. História das rádios populares. Introdução à comunicação oral e sua manifestação nos grupos sociais populares. Apresentação, discussão e prática das principais linguagens e formatos orais.

- Internet - Noções de comunicação digital e do universo hipertextual.

\section{Leitura crítica}

Finalmente, o curso oferece um módulo de aulas e discussões teóricas com o objetivo de permitir ao aluno ampliar o seu olhar para as realidades sociais, políticas, culturais e econômicas do mundo atual, orientando sua práxis comunicativa. Este módulo, designado como "Leitura crítica", visa o desenvolvimento de uma consciência crítica do aluno em relação aos produtos veiculados na mídia, buscando capacitá-lo a perceber e desconstruir os pressupostos ideológicos que estão presentes nas entrelinhas do discurso jornalístico, publicitário e nos programas de entretenimento.

Se os meios comunitários se propõem a difundir uma representação contrahegemônica - marginal - da realidade, considera-se que o trabalho do repórter comunitário não pode seguir o padrão da grande imprensa. Não adiantaria de nada ensinar aos jovens da favela uma técnica comunicacional, sem lhes oferecer um instrumental teórico que lhes permita a crítica da informação tecnologizada da sociedade mercantili e uma "compreensão" aprofundada de sua própria realidade. Se a ESPOCC fosse apenas uma escola técnica, os alunos correriam o risco de reproduzir acritica e mecanicamente o conteúdo da grande mídia.

Nas aulas de "Leitura crítica", professores de diversas áreas - comunicação, história, antropologia, cinema e serviço social - procuram desenvolver uma reflexão sobre a cidade - sua história, suas representações, suas relações de poder, seus conflitos - a partir da perspectiva dos espaços populares.

Toda essa discussão visa a construção de um outro discurso sobre a favela e o favelado, um outro olhar sobre as comunidades da periferia, diferente daquele construído pela grande mídia. Esta é, com efeito, a proposta do idealizador da Escola, Jailson de Souza. Segundo ele, os espaços populares - as chamadas favelas - 
historicamente habitam o imaginário social sob a representação dos "discursos de ausência e do preconceito". É o lugar do pobre, do favelado, do bandido, do desregrado, do vulgar e qualitativos do mesmo campo semântico. Seu lugar nos jornais costuma ser a seção policial. Sintomaticamente, as práticas e estratégias desenvolvidas no cotidiano pelo morador são esquecidas no discurso da mídia, que não leva em conta os aspectos afirmativos, integrantes de sua cotidianidade", ou seja, a vida comuntária, suas dinâmicas culturais, as iniciativas pedagógicas, a solidriedade, as formas de resistência à violência do tráfico e da polícia, as lutas contra a opressão, etc.

Jailson de Souza considera que a produção de mensagens midiáticas, particularmente aquelas sobre os espaços populares, são construídas, nos meios de massa, por indivíduos que não possuem uma relação orgânica com o universo das camadas subalternas. Os próprios jornalistas, oriundos dos setores médios, expressam, em larga medida, os preconceitos e as concepções ideológicas do grupo social a que pertencem. Daí a necessidade de se conceber uma produção estéticodiscursiva capaz de expressar as formas de consciência, a fala histórica dos moradores do bairro.

Segundo os coordenadores da Escola, somente uma mídia comunitária que atue na produção de discursos, imagens, informações elaborados a partir da ótica do morador poderá cumprir o atendimento de suas demandas sociais no campo da produção e da partilha da informação, representando, efetivamente, as diversas entidades e grupos que compõe a vida nessas localidades.

Nessa perspectiva, a ESPOCC deve atuar, estrategicamente, em dois sentidos, sendo o primeiro a construção de uma rede de comunicação alternativa na cidade, incentivando e dando suporte à criação de TVs de rua, jornais impressos, cartilhas, rádios livres e comunitárias. $\quad$ E o segundo, a efetivação de um canal de diálogo com os meios de comunicação de massa constituídos, de maneira que seja possível interferir na discussão sobre a representação das comunidades populares na grande mídia. Nesse sentido, trata-se de ocupar espaços disponíveis, atuar nas brechas por onde possa florescer uma visão de mundo alternativa. Esta estratégia envolve a consideração de que "a mídia não é um espaço homogêneo, sem contradições, no qual vigora tão-somente a manipulação sistemática da opinião 
pública”. A luta pela cultura pressupõe a conquista de espaços na chamada grande mídia. Afinal, a comunicação comunitária não pretende se isolar do resto o mundo. Parafraseando Tolstoi, o repórter popular, tal como o poeta, quando canta a sua aldeia almeja a universalidade.

Começamos falando que a ESPOCC aparece como uma auspiciosa novidade no cenário político-cultural da cidade, uma alternativa concreta ao monopólio dos meios de comunicação. Trata-se, de fato, de um projeto novo que pretende consolidar-se nos próximos dez anos, devendo ainda ser implantado em outras regiões da cidade com o mesmo formato. No entanto, embora seja uma proposta inédita no Rio de Janeiro, é preciso que se diga que a Escola é uma iniciativa que retoma e atualiza lutas e esforços históricos de diversas organizações sociais pela construção de uma nova ordem de comunicação no Brasil.

Formando repórteres populares, a ESPOCC dá continuidade a processos contra-hegemônicos na imprensa carioca; não como uma instituição que pretende falar pelo povo, mas como uma escola que cria condições para que as comunidades possam expressar sua fala histórica - marginal e popular.

\section{BIBLIOGRAFIA}

ATHAYDE, Phydia de. "Rádios comunitárias lutam para não ser fechadas nem apropriadas por políticos ou religiosos", www.portalpopular.org.br.

CASTILHO, Carlos Volkmer. "Proposta para a observação dos meios". http://observatorio.ultimosegundo.ig.com.br/coloquio/index.asp.

GRAMSCI, Antonio. Os cadernos do cárcere. Rio de Janeiro: Civilização Brasileira, 2001.

HERZ, Daniel. História secreta da Rede Globo. Ed. Tchê, 1983.

PAIVA, Raquel. O espírito comum - mídia, comunidade e globalismo. $2^{\mathrm{a}}$. Ed. Rio de Janeiro: Mauad, 2002.

PERUZZO, Cecília Maria K. Petrópolis: Vozes, 1998. 
SODRÉ, Muniz. O monopólio da fala: função e linguagem da televisão no Brasil. Petrópolis: Vozes, 1977.

SODRÉ, Nelson Werneck. História da imprensa no Brasil. 3a.ed. São Paulo: Martins fontes.

SOUSA, Helena. "Time-Life/ Globo/ SIC: um caso de exportação do modelo americano de televisão?” http://ubista.ubi.pt.

SOUZA, Jailson de. Uma nova escola de comunicação, popular e crítica. Trajectos Revista de Comunicação, Cultura e Educação, n.6. ,Lisboa, 2005. 